\title{
Education Research (SSEER 2020) Study on the Strategy of the Industrial Leapfrogging Engine in Hubei Under the New Circumstance
}

\author{
Zhihong Li* \\ Business School \\ Jianghan University \\ Wuhan, China 430056
}

\begin{abstract}
The quick evolution of the hi-tech like the new generation information, the big data, new energy and the cloud computation,etc is causing a dramatic revolution whether in social life or in production or else. In this condition, a new reform in the industry is coming near. How the industry leapfrogs in Hubei by fully using its relatively complete industrial system is worthy to be studied. So, the paper first expounds the concerned requirements, then analyzes the actual industrial situation, next explores the power to stimulate the further development of the industry, finally proposes the correspondent strategy under the new conditions.
\end{abstract}

Keywords-strategy; industrial leapfrog; engine; new circumstance

\section{INTRODUCTION}

In recent years, the circumstance in which the industry lies has been dramatically changing. The coming of the third industrial revolution, the quick evolution of the big data technology and the mushroom of the internet+ and so forth are changing the production and life of the human being in the root. Take it for example, billions of people may produce their own green energy at home or in the office or in the factory and share it on the internet of energy. All these changes are restructuring the relationship among people and affecting our production \& business models, management institutions and rules.

\section{REQUIREMENTS OF THE TECHNOLOGY, PRODUCTIVE} STYLE, BUSINESS MODELS AND MANAGEMENT INSTITUTIONS

First, the combination between the technologies in the internet and big data and the recyclable energy lays a fond foundation for the industrial reform. In light of Jeremy $\cdot$ Rifkin $^{[1]}$, the third industrial revolution has five pillars: transformation to the recyclable energy, small power station construction, energy generation and storage expanded to all the infrastructure, the traffic system of electricity charge and the internet of energy. This kind of sharing mechanism based on the internet makes everyone become producers and then changes the traditional process, marketing, transportation, logistics and other service. Of all these technologies, the mature $3 \mathrm{D}$ printing ${ }^{[2]}$ is the key to realize the reform. Then in the productive style, different from the traditional concentrated production, the reformed industry can use the $3 \mathrm{D}$ printing to produce the product step by step according to the relative software. In the business model ${ }^{[3]}$, due to the sharing mechanism of the productive elements, the reformed industry under the new circumstance tends to the lateral scale rather than the vertical scale, which is helpful to the cooperative business. The distributive information, network and communication, combined with the scattered recyclable energy, requires a synergy in the administration, and horizontal expansion in the operation among industry, government and citizens. In this way, various small stores, office and family can be connected by WIFI and share what they have or want.

\section{ACTUAL SITUATION OF THE INDUSTRIAL DEVELOPMENT IN HUBEI}

By the end of 2019, the industrial enterprises on the abovescale had reached 15589 in Hubei. The industrial production keeps rising with an added value of $7.8 \%$. Also, the structure of the industrial outcome has been further improved. The light industry rises by $6.8 \%$ while the heavy industry goes up by $8.2 \%$, of which the manufacturing industry increases by $7.9 \%$ with 0.1 percentage higher than that of the above-scale industry; the hi-tech industry increases by $14.4 \%$ with 6.6 percentage higher than that of the above-scale industry, occupying $9.5 \%$ of its added value and having contributed $17.0 \%$ to it. At the same time, the making in the computers, communication and other electronic equipment goes up by $19.0 \%$ and that in electric machinery and apparatus rises by $11.0 \%$. Besides, the industrial outcomes and sales are well linked up with increased economic benefits. The yearly abovescale industrial output value of sales rises by $7.8 \%$ with a sales rate of $97.2 \%$. The yearly above-scale industrial enterprises realize a profit of 286.78 billion yuan and goes up by $4.0 \%{ }^{[4]}$.

\section{ANALYSIS OF THE INDUSTRIAL ENGINE IN HUBEI UNDER THE NEW CIRCUMSTANCE}

Having been developed for decades of years, the industry in Hubei has had a good foundation ${ }^{[5]}$ able to meet with the requirements of the new circumstance. First, thousands of the mid-small enterprises can use the $3 \mathrm{D}$ printing to provide what the consumer has customized in the conditions of the built infrastructure like new energy, new architecture, energy storage $\&$ internet and traffic logistics,etc. Also, in the course of 
processing, the local community can generate the green electric power and make the processing cost of 3D products nearly zero. Thus, it is unnecessary for these enterprises to rely on the traditional energy like petroleum or else. Then, under the new circumstance, the big data technology, the internet+ and so forth are overturning people's cognition. New chances and challenges are appearing either in life or in employment or in communication,etc. The industrial enterprise should be sensitive to these changes and capture the chances to locate the target market. Next, once the infrastructure under the new circumstance has been perfected, marketing is almost free, so is the logistic service due to the wide use of the green energy. Moreover, the lateral scale in the business model may do more benefits to the cooperative organization of the enterprise. To be summarized, in leapfrogging, the engine ${ }^{[6]}$ of the industry in Hubei mainly lies in the energy gap: the traditional energy is being replaced by the recyclable one and the exploration, utilization and storage of the recyclable energy is the lasting engine to develop the industry in Hubei.

\section{STRATEGY OF THE INDUSTRIAL LEAPFROGGING ENGINE IN HUBEI UNDER THE NEW CIRCUMSTANCE}

\section{A. Energy Transformation Strategy}

With the exhaustion of the traditional energy step by step, it is inevitable for the recyclable energy to substitute the traditional energy ${ }^{[7]}$. Outlook Report of the Global Energy 2010 from the International Energy Agency says that the global crude oil has reached the peak output in 2006 while everyday demand volume is seven thousand tanks at that time. The continuous reduction of the deposits of the crude oil can't meet with the rising demand in the market. As a result, the price of the crude oil in the international market keeps shooting up. Luckily, due to the break-through of the relative technology and the scale economy, new recyclable energy like photovoltaic generation is rising in the outputs and dropping in the price. According to some research, the cost of the photo-voltaic generation is expected to be lowered at the rate of $8 \%$. At the same time, the substitution of the traditional energy by the recyclable energy is sure to derive certain new economic style and management models. Therefore, the industrial leapfrog under the new circumstance is obliged to realize its energy transition from relying on the traditional energy to using the recyclable energy.

\section{B. Energy Internet System Construction}

The highly integration ${ }^{[8]}$ between the internet information technology and the recyclable energy is the typical model of the new economic conditions. Compared with the traditional electronic communication technology such as telephone, TV and radio, the internet information technology is more suitable for managing the distributive recyclable energy and for the downsized business activity. In the coming future, every building is a mini power station and everyone is an independent producer of the green energy. Also, every energy producer can share his energy with others by an outer net-typed intelligent distributive electric system. The development, storage, use and popularization of the recyclable energy will make each building become both a house and a mini power plant.

\section{Technological Exploration \& Use of the 3D Printing}

Under the new circumstance, the connection among the information \& internet technology, auto-control and industrial processing technologies becomes closer and closer. We can print the product like clothing, mould and parts by using 3D printing ${ }^{[9]}$ based on these technologies. The traditional tools such as lathes, drillers and punches will be replaced by the 3D printer. The big data, artificial intelligence and new materials can be widely used. The industrial robot substitutes the worker on the productive line with fewer costs and higher efficiency.

\section{Sharing Mechanism Based on the Energy Internet ${ }^{[10]}$}

In the history, any revolution in the industry is accompanied with the innovation and improvement of the management and institutions. During the first industrial revolution, the replacement of the hand-made printing by the steam engine printing pushes the quick transmission of the information due to the large quantity of the low cost printing. People use the new communication system to manage the new energy system based on the coal. During the second industrial revolution, with the appearance of concentrated electricity, telephone and wireless,etc, the linkage between the communication and energy makes it possible to manage the complicated petroleum tube network, the automobile route network and so on. On the base of this, the urban culture springs up. Now, the new generation information technology, internet and big data,etc in the new circumstance are bringing us a dramatic change whether in life or in production or in operation. Take it for example, the distributive information and communication technology is being integrated into the distributive recyclable energy, which is the base of the coming third industrial revolution. The scattered energy must be managed in synergy and extended laterally. The comanagement relies on the sharing mechanism of the energy and information based on the internet. In this way, the industry, government and citizens should be closely cooperated and innovate an institutional and administrative model adaptive to the third industrial revolution.

\section{CONCLUSION}

The fast development of the new technology in information, network, new materials and new energy,etc brings both challenges and opportunities to the industry. In spite of having an intact system, the industry is obliged to better use the opportunities so as to cater for the new conditions and avoid the risks. Therefore, the industry should find out the power source from the new technology and then formulate the precise strategy to orient the quick reform of the industry. Only in this way can the industry be sped up into the mainstream of the new industrial reform and capture the chance to enter the higher end of the industrial chain.

\section{ACKNOWLEDGMENT}

The paper is funded by the Discipline Group of the Integrative Management Between Economy and Industry in the 
City Circle, by the Wuhan Studies Institute, Hubei, China (IWHS20172001), and by Research Center on the Development of the Manufacturing Industry of the Wuhan City Circle, China (wz201607).

\section{REFERENCES}

[1] Jeremy-Rifkin. The Third Industrial Revolution: How the New Economic Model Changes the World(translated by Tiwei Zhang, Yuning Sun). Zhong Xin Press, June 2012.

[2] Guowei Zhao. Outlook of the 3D Printing Technology Research, Southern Agricultural Machinery. No.9,2019, p26.

[3] Birth of the New Business Model Made by the Third Industrial Revolution, IT Manager World, Aug.30, 2012,http://www.im2m.com.cn/.
[4] Statistics Communique of the National Economic and Social Development in Hubei in 2019, Hubei Journal, 2020-03-23 07:21 http://www.hubei.gov.cn/zwgk/hbyw/hbywqb/202003/t20200323_21877 65.shtml.

[5] Xuan Wang. Actual Situation and Countermeasures of the Industrial Development in Hubei. Economic School, Huazhong University of Science and Technology, Aug.6, 2013.

[6] 42 Significant Increase Highlights \& Industrial Engine in Hubei,07:43, Jan.2, 2018.

[7] Shi Yao, Xiaoming Wang. How the Enterprise Faces the Thire Industrial Revolution, No.1, Everyday Telecommunication Xin Hua, Sept.7, 2012.

[8] Qian Liang, Yunlong Hou. Linkage to the Third Industrial Revolution by Integration Between the Information and Industrialization, Economic Reference Journal, July 4, 2012.

[9] Qingping Hong. Application and Influence of the 3D Printing Technology in the Industrial Design, Guide to the Enterprise, No.16,2016.

[10] Long Xia, Qi Tan. Review on Energy Internet Research, Sustainable Energy. 8(5), 2018, pp53-59. 